
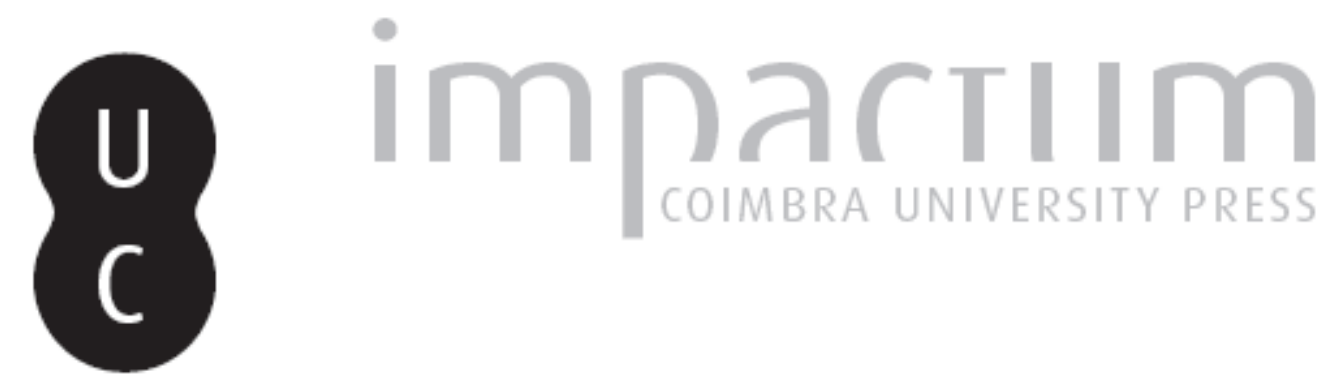

\title{
[Recensão a] Marie-Helène e Jacques Santrot, Céramiques communes gallo- romaines d'Aquitaine
}

\author{
Autor(es): $\quad$ Alarcão, Jorge de \\ Publicado por: Imprensa da Universidade de Coimbra \\ URL \\ persistente: \\ URI:http://hdl.handle.net/10316.2/45727 \\ DOI: \\ DOI:https://dx.doi.org/10.14195/1647-8657_19_7 \\ Accessed : $\quad$ 26-Apr-2023 15:10:19
}

A navegação consulta e descarregamento dos títulos inseridos nas Bibliotecas Digitais UC Digitalis, UC Pombalina e UC Impactum, pressupõem a aceitação plena e sem reservas dos Termos e Condições de Uso destas Bibliotecas Digitais, disponíveis em https://digitalis.uc.pt/pt-pt/termos.

Conforme exposto nos referidos Termos e Condições de Uso, o descarregamento de títulos de acesso restrito requer uma licença válida de autorização devendo o utilizador aceder ao(s) documento(s) a partir de um endereço de IP da instituição detentora da supramencionada licença.

Ao utilizador é apenas permitido o descarregamento para uso pessoal, pelo que o emprego do(s) título(s) descarregado(s) para outro fim, designadamente comercial, carece de autorização do respetivo autor ou editor da obra.

Na medida em que todas as obras da UC Digitalis se encontram protegidas pelo Código do Direito de Autor e Direitos Conexos e demais legislação aplicável, toda a cópia, parcial ou total, deste documento, nos casos em que é legalmente admitida, deverá conter ou fazer-se acompanhar por este aviso.

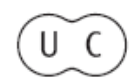


FACULDADE DE LETRAS

INSTITUTO DE ARQUEOLOGIA

CONIMBRIGA

VOLUME XIX

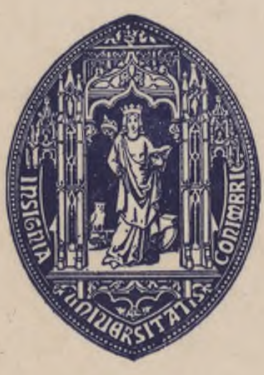

UNIVERSIDADE DE COIMBRA

1980 


\title{
RECENSÕES BIBLIOGRÁFICAS
}

\author{
Marie-Helène e Jacques S An T rot, Céramiques communes gallo-romaines \\ d'Aquitaine. Paris, C.N.R.S., 1979, 1 vol., 266 p., 133 est.
}

A obra de M. H. e J. Santrot é uma séria e prudente abordagem da cerâmica comum galo-romana da Aquitânia. O conceito de cerâmica comum, como os autores observam, é um conceito impreciso, residual: excluídas aquelas categorias de cerâmica romana hoje perfeitamente identificadas e já com larga bibliografia específica, como a sigillata, a sigillata clara, a cerâmica estampada tardia paleocristã (esta última designação é a dos autores, não a minha), a cerâmica de paredes finas e umas quantas outras, o resto agrupa-se e estuda-se sob a designação de cerâmica comum. «Elle représente les «laissés-pour-compte» de la céramique».

Os estudos meramente tipológicos conduzem a um recenseamento das formas e constituem um trabalho preliminar ao estabelecimento da cronologia; não permitem, porém, caracterizar grupos, atribuí-los a oficinas localizáveis no espaço e no tempo, estudar o comércio da cerâmica - pois a maior parte das formas constitui um reportório comum a várias oficinas geográfica e cronologicamente distantes. Os autores têm perfeita consciência deste facto; e se optam por um estudo essencialmente tipológico, fazem-no por razões que claramente indicam e justificam. A identificação das oficinas será sempre dutfdosa enquanto não houver estudos físicos e químicos das pastas e escavações de centros fabricantes. É certo que, para além das pastas, as produções locais podem caracterizar-se por aspectos tecnológicos de acabamento, de cozedura, bem como pelos motivos decorativos (quando existam) e, até certo ponto, pelas formas: muitas destas, como se disse, são comuns a várias oficinas; mas há por vezes formas típicas e próprias de certos centros, e mesmo as formas mais comuns podem eventualmente ser diversificadas por pequenos pormenores. Ora, os estudos de pastas estão no início (e reconheça-se aos autores o mérito de terem já bastante contribuído para eles) e são escassas as escavações de oficinas cerâmicas na área considerada nesta obra (escavações que constituem objecto de um pequeno capítulo). «A classificação por categorias de pastas seria, sem dúvida, significativa, mas é prematura» (p. 41). Nestas circunstâncias, a perspectiva tipológica pareceu aos autores 
menos aventureira. Cada tipo (ou cada for ma, na nomenclatura francesa dos autores) tem uma descrição de pasta, rigorosa sem excessos de pormenor, que permite fazer aproximações e sugerir proveniências. Assim, o estudo aparentemente formal cruza-se com o estudo tecnológico cujos resultados poderiam ter sido todavia sistematizados num capítulo final. Segundo os autores (p. 9), será possível, neste momento, identificar já uma dezena de produções diferentes. Uma caracterização, mesmo preliminar, de cada uma, eis o que falta, de forma sistemática, neste volume.

O estudo baseia-se no exame de nove colecções de Bordeaux e Saintes, num total de 1469 vasos, sem contar algumas centenas de milhares de fragmentos que terão sido lavados e examinados um a um. Os autores apresentam um «dicionário» de 515 formas, algumas delas subdivididas e, na maior parte, ilustradas por perfis completos.

Tipos, para os autores, são as grandes categorias funcionais ou morfológicas em que as formas se classificam: testos, pratos, taças, almofarizes, picheis, bilhas, etc. Cada forma é descrita, caracterizada, como se disse, tecnologicamente e, quando possível, datada. As datas, de um modo geral, não são justificadas; os autores advertem (p. 8) que foram deduzidas dos contextos arqueológicos e não estabelecidas, salvo casos devidamente assinalados, por comparação com formas idênticas de outras regiões da Gália ou de fora da Gália.

A definição dos tipos parece, na generalidade, correcta ou, pelo menos, operacional. Talvez ou autores devessem ter levado mais fundo a análise das funções dos vários tipos: louça de mesa ou de cozinha, vasos para sólidos ou líquidos, vasos para beber ou para transportar líquidos, etc. Isso poderia tê-los conduzido à adopção de outros tipos, como frigideiras (poêles), tachos poêlons), terrinas (terrines), tigelas ou malgas (bois ou écuelles), taças, (jattes) copos (gobelets), etc. Maior número de tipos poderia ter conduzido a melhor arrumação das formas. Neste capítulo, há alguns reparos a fazer. Assim, incluem-se nos pratos algumas formas que não correspondem ao índice adoptado: diâmetro: altura $\wedge 4$; na categoria dos «pichets» encontram-se formas tão divergentes como 347 e 356 ; entre os potes incluem-se peças que devem ter funcionado de copos, ou o n. ${ }^{\circ} 325$, aliás correctamente interpretado como garrafa (bouteille). Há que reconhecer, todavia, que a incerteza é grande quanto às funções das peças, e que o assunto não foi de forma alguma descurado pelos autores. As relacionações que M. H. e J. Santrot fazem entre formas de vasos e hábitos alimentares são judiciosas.

A obra é dividida em três partes fundamentais. Na primeira - Técnicas de fabrico, decorações e marcas - explicam-se, de forma concisa e clara, conceitos fundamentais, caracterizam-se processos tecnológicos, tomam-se posições críticas relativamente a pontos importantes como o da preparação das pastas, estabelecem-se tipologías e nomenclaturas de decorações e cozeduras, estudam-se 10 marcas (6 das quais, em almofarizes).

$\mathrm{Na}$ segunda parte - Formas — os autores justificam os critérios usados na ordenação das formas. Abandonaram, o que nos parece justo, a ideia de 
uma apresentação de acordo com modelos formais estabelecidos por computador; esta posição é muito de ter em conta, dado que não é uma atitude a priori, mas, pelo contrário, uma posição conscientemente assumida depois de ensaios que os autores fizeram no computador a partir de um código de descrição analítica da cerâmica comum galo-romana. Segue-se, nesta segunda parte, o inventário e descrição das formas. Para várias delas poderiam, certamente, citar-se muito mais paralelos; mas isso seria estendal de erudição sem resultados práticos positivos. Os paralelos são citados, não para justificar cronologias ou sugerir proveniências, mas, pelo contrário, para mostrar como formas semelhantes podem aparecer em datas diferentes e em regiões afastadas.

A introdução de testos e tampas de ânforas numa obra que não considera esta categoria de cerâmica é certamente discutível, bem como a apresentação dfó n. ${ }^{\circ} 370$, que nos parece ser um colo de ânfora. A presença de vários mealheiros (forma aliás rara nas outras regiões do Império) é sensatamente atribuída a uma moda criada por qualquer oleiro burdigalense.

$\mathrm{Na}$ terceira parte da obra, sobre a difusão das cerâmicas comuns, um quadro (p. 218-219) sistematiza as semelhanças de várias formas de cerâmica comum com vasos de vidro e de bronze, cerâmica campaniense e sigillata. O quadro não é, obviamente, exaustivo, mas serve para lançar certas dúvidas sobre a ideia geralmente admitida de que a cerâmica imitou o vidro, o bronze, a prata; ao contrário, as formas da cerâmica comum terão sido, segundo os autores, os modelos originais que o vidro, o bronze ou a sigillata imitaram. Os exemplos não nos parecem suficientemente abundantes nem as cronologias suficientemente rigorosas para demonstrar uma tese que, todavia, merece ser considerada como plausível. Mais próximos dos utentes, os oleiros responderiam, primeiro que os fabricantes de vasos de vidro ou de bronze, às necessidades do público.

As formas não são criações individuais, mas colectivas (p. 222); consequentemente, não poderá falar-se de «difusão» de uma forma a partir de uma oficina, mas de aparecimento simultâneo, explicável por um património cultural e um desenvolvimento técnico comuns.

O problema da circulação é objecto de um pequeno capítulo que manifestamente se opõe à ideia de que as cerâmicas comuns viajaram pouco, ou seja, que a área de exportação a partir de uma dada oficina sempre foi. para a cerâmica comum, restrita. Quanto a este aspecto, todas as generalizações são aventureiras. A identificação de oficinas e a caracterização rigorosa das respectivas pastas e formas é condição sine qua non de qualquer estudo aceitável de circulação, estudo esse que, por outro lado, terá de ter em conta dados estatísticos, bem como a rede de vias e a malha dos povoados. Não foi neste sentido que a obra se orientou. Assim, este capítulo não ultrapassa o nível de algumas ideias gerais, todavia úteis, como, por exemplo, a distinção entre circulação ocasional e importação sistemática, ou a observação de que a ausência, na Aquitânia, de cerâmicas importadas da Bélgica ou da Germânia se pode explicar pelo facto de a Aquitânia produzir cerâmica que correspondia 
às mesmas necessidades e funções que as cerâmicas romano-belgas ou romano-germânicas.

Um léxico dos nomes latinos dos vasos, relacionados com os tipos considerados nesta obra, um dicionário dos termos técnicos usados, e uma bibliografia não isenta de erros (vid. sob os nomes de Alarcão, Delgado, Lamboglia), completam o volume.

Os desenhos, obviamente feitos por mais de um desenhador, usando várias convenções, são bons, embora a impressão seja responsável por alguns borrões e empastamentos que prejudicam o aspecto estético sem tornarem todavia difícil a leitura.

O «dicionário» de formas de M. H. e J. San trot vai ser sem dúvida utilíssima obra de referência para os arqueólogos da Aquitânia romana; esperamos que os autores, de cuja capacidade esta obra é inequívoco testemunho, prossigam os seus estudos, orientando-os naquela direcção que consideram a mais significativa, embora, por enquanto, prematura.

Jorge de Alarcão

\section{Carol Kramer, E thno-archaeology. Implications of Ethnography for Archaeology. New York, Columbia University Press, 1979. 1 vol., 292 p., il.}

A etno-arqueologia, que alguns autores designam por arqueo-etnografía ou etnografia arqueológica, é uma disciplina recente. Pelos métodos, será uma subdivisão da etnografia; pelos objectivos, individualiza-se como uma disciplina que pretende, estudando a cultura material dos povos primitivos ou das comunidades rurais da actualidade, auxiliar a interpretação dos dados arqueológicos, ou mesmo a prospecção dos sítios. A etno-arqueologia tem contribuído, nos últimos anos, para uma transformação da arqueologia, de mera classificação e ordenação cronológica dos artefactos, no sentido de uma investigação das estruturas socio-económicas e socio-culturáis dos povos pré-históricos.

«A etno-arqueologia investiga aspectos dos comportamentos sócio-culturais contemporâneos numa perspectiva arqueológica» (p. 1); por outras palavras, não se limita a definir modelos de funcionamento sócio-cultural (pois então seria antropologia cultural), mas pretende investigar que cultura material lhes corresponde. «Muitos etnógrafos não têm fornecido, nas últimas décadas, quadros sistematizados da cultura material das sociedades que descrevem; ora, é precisamente a cultura material que constitui a essência dos vestígios arqueológicos» (p. 5). A atenção dos etno-arqueólogos concentra-se no estudo da cultura material dos povos primitivos ou das comunidades rurais contemporâneas, mas investiga as estruturas sócio-económicas ou sócio-culturais que determinam essa cultura material. Assim, quando o arqueólogo encontra idênticos restos materiais, poderá suspeitar da existência das mesmas estruturas sociais. Quando encontra idênticos objectos dispostos 